\title{
Entry and Competition in Generic Biologics
}

\author{
Henry G. Grabowski*, David B. Ridley and Kevin A. Schulman \\ Health Sector Management Program, The Fuqua School of Business, Duke University, NC, USA
}

\begin{abstract}
Patents for several blockbuster biological products are expected to expire soon. The Food and Drug Administration is examining whether biologics can and should be treated like pharmaceuticals with regard to generics. In contrast with pharmaceuticals, which are manufactured through chemical synthesis, biologics are manufactured through fermentation, a process that is more variable and costly. Regulators might require extensive clinical testing of generic biologics to demonstrate equivalence to the branded product. The focus of the debate on generic biologics has been on legal and health concerns, but there are important economic implications. We combine a theoretical model of generic biologics with regression estimates from generic pharmaceuticals to estimate market entry and prices in the generic biologic market. We find that generic biologics will have high fixed costs from clinical testing and from manufacturing, so there will be less entry than would be expected for generic pharmaceuticals. With fewer generic competitors, generic biologics will be relatively close in price to branded biologics. Policy makers should be prudent in estimating financial benefits of generic biologics for consumers and payers. We also examine possible government strategies to promote generic competition. Copyright (C) 2007 John Wiley \& Sons, Ltd.
\end{abstract}

\section{INTRODUCTION}

The Food and Drug Administration (FDA) is examining whether biological products can and should be treated like pharmaceuticals with regard to generics. The focus of the debate on generic biologics ${ }^{1}$ has been on legal and health concerns, but there are important economic questions. How will differences in development and manufacturing costs and associated regulations affect the market for generic biologics? Will generic biologics be as competitive and provide the substantial financial savings provided by generic pharmaceuticals? We analyze market entry and prices in the generic biologic market using a theoretical model of generic biologics and regression estimates from generic pharmaceuticals.

*Correspondence to: Department of Economics, Box 90097, Durham, NC 27708-0097, USA. E-mail: grabow@econ.duke.edu
There have not yet been any major market approvals of generic biologics due to three barriers. First, the biotechnology industry is young, so few patents have expired for major biologic products. Second, the regulatory framework for generic biologics has not been settled. Third, biologic products are complex and have high costs of establishing scientific and manufacturing capabilities (Humphreys, 2004).

The first two barriers might fall soon. First, by 2007 patent expirations are expected for blockbuster biologics such as Procrit, Epogen, and Intron A (Humphreys, 2004). Second, FDA is considering guidelines for the approval of generic biologics. ${ }^{2}$ The third problem of complexity and high costs will likely limit but not blockade entry of generics.

Biologics differ from pharmaceuticals in many respects. Pharmaceuticals are small molecules, can be chemically synthesized, and are orally available. Biologics are large molecules, are created through 
biologic processes such as fermentation or cell culture then purified, and require special delivery systems such as injections into the bloodstream because they are readily degraded by the digestive system. Manufacturing biologics is more variable and costly than manufacturing pharmaceuticals and includes expensive biologic process development in conjunction with the FDA. Regulators might require extensive clinical testing of generic biologics to demonstrate equivalence to the branded product.

Ours is the first published study that models the generic biologic market from an economic perspective. ${ }^{3}$ There is, however, an important body of work in economics on market entry and competition (e.g. Bresnahan, 1989). Bresnahan and Reiss, (1991) suggest that after the third firm enters a market, prices are near the perfectly competitive level. Furthermore, there has been a focus on entry and competition in the generic pharmaceutical industry because of its policy relevance and implications for health care expenditures (Caves et al., 1991; Grabowski and Vernon, 1992; ScottMorton, 1996; Wiggins and Maness, 1996; Frank and Salkever, 1997; Reiffen and Ward, 2005; Saha et al., 2006). For example, using data on generic pharmaceuticals from the early 1990s, Reiffen and Ward (2005) find substantial differences in entry between large and small markets with large markets more likely to have many entrants and marginal cost pricing. In addition, studies by a Canadian think tank and US Health and Human Services suggest that average prices for generic pharmaceuticals are higher in Canada than in the United States, perhaps because Canada has a smaller market size and higher fixed costs of entry due to regulations (Alonso-Zaldivar, 2005; Skinner, 2005).

In previous studies of generic pharmaceutical manufacturers, one or two entrants had only limited impact on prices; it was the entry of multiple generic firms that was responsible for the substantial differences in prices between branded and generic products in the US market. Will the generic biologic market induce sufficient entry to drive down prices? To assess this question we must consider entry decisions by firms when examining whether to produce a specific generic product. When contemplating such an investment, firms consider fixed costs, variable costs, and market size. If firm entry in the generic biologic market is not as vigorous as for pharmaceuticals, then price discounts for generic biologics will be smaller than for pharmaceuticals.
We combine a theoretical model of generic biologics with regression estimates from generic pharmaceuticals to estimate market entry and prices in the generic biologic market. We find that generic biologics will have higher fixed costs from clinical testing and from manufacturing, so there will be less entry than would be expected for generic pharmaceuticals. With fewer generic competitors, generic biologics will be relatively close in price to branded biologics.

Consider a half-billion-dollar product 12 months after the entry of the first generic manufacturer. If generic biologics are like generic pharmaceuticals, except that fixed costs for biologics are $150 \%$ higher, then we estimate that there would be 9 generic pharmaceutical manufacturers but only 2 generic biologic manufacturers. With 9 entrants the generic price would be $44 \%$ of the branded price, but with 2 entrants the generic price would be $82 \%$ of the branded price. Furthermore, if the fixed costs of generic biologic manufacturers were even higher, fewer competitors would enter and generic prices would be higher too.

The estimates from our model abstract from a number of potentially significant factors and are not intended as a forecast of what will happen in the markets for specific biologic products subject to patent expiration. They are intended to illustrate, however, the very important role that fixed costs are likely to play in determining entry and price competition in the market.

In the next section we describe our methodology of combining a theoretical model of generic biologics with regression estimates from generic pharmaceuticals to estimate market entry and prices in the generic biologic market. In the following section we report our results, and in the final section we discuss our findings and consider policy options.

\section{METHODS}

Our methodology can be summarized as follows. First, we characterize the market for generic biologics and solve for elasticity of entry as a function of fixed costs. Second, we compare cost differences between pharmaceuticals and biologics. Third, we estimate market entry for generic pharmaceuticals as a function of market size to inform our understanding of generic biologics. 
Fourth, we estimate relative prices for generic pharmaceuticals as a function of the number of manufacturers. Fifth, we use the theoretical model and empirical findings to simulate market entry and prices for generic biologics.

\section{Theory of Monopolistic Competition}

We model the market for generic biologics in order to better understand how manufacturers respond to changes in market structure such as costs. We characterize the market for generic biologics as monopolistic competition (Chamberlin, 1933). The market is competitive in that there is free entry and exit. Of course, the FDA regulates entry of generics, but it does not limit the total number of generics. Because of free entry, in the long run we do not expect generic manufacturers to earn above-normal profits in a particular therapeutic molecule. We expect that generic manufacturers will continue to enter the market until the expected profits for a given product are normal. The market is not, however, perfectly competitive; there are significant entry costs on the supply side of the market.

The focus of our theoretical modeling is to analyze how these costs affect entry and in turn how entry affects the equilibrium of generic price relative to the pre-entry monopoly price. The price ratio is a key dependent variable of interest in our empirical analysis. In our theoretical model, we abstract from strategic behavior on the part of the branded firm. In particular, for a given molecule we treat all sellers (branded and generic) as symmetric following patent expiration, so one price will prevail in long-term equilibrium. This equilibrium price will be determined by the zero profit conditions for entrants in our model. ${ }^{4}$

We model the market using a simple inverse demand function, $p=a-b Q$, where $p$ is the price and $Q$ is the sum of the output produced by $N$ identical firms. The cost facing firm $i$ is $C\left(q_{i}\right)=m$ $q_{i}+F$ where $m$ is the constant marginal cost and $F$ is the fixed cost. We can solve for a firm's best response function: $q_{i}=\left(a-m-b(N-1) q_{j}\right) / 2 b$ where $q_{j}$ is the output of one of the other $N-1$ identical firms. Given this symmetry, $q_{i} *=(a-m) /(b+b N)$. Setting profits equal to zero (due to free entry) and solving for $N$ yields the following:

$N^{*}=\frac{a-m}{\sqrt{b} \sqrt{F}}-1$.

Copyright (C) 2007 John Wiley \& Sons, Ltd.

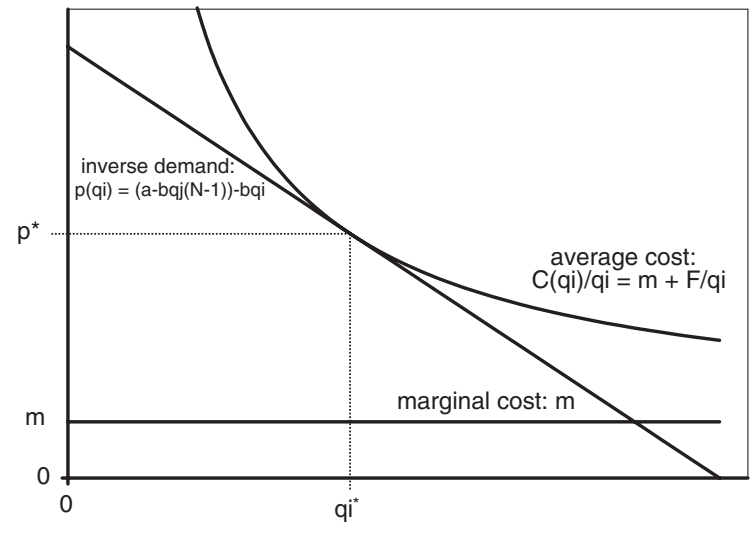

Figure 1. Free entry increases the number of manufacturers until each manufacturer's inverse demand function is tangent to its average cost function. At this point $\left(q_{i} *\right)$, each manufacturer earns normal economic profits and entry ends.

According to Equation 1, the equilibrium number of firms decreases with fixed costs and marginal costs. An important difference between pharmaceuticals and biologics is the cost of production. If fixed costs $(F)$ or marginal costs $(m)$ are higher for biologics, then equilibrium market entry $\left(N^{*}\right)$ will be smaller for a given level of sales.

Figure 1 illustrates the equilibrium. Free entry increases the number of manufacturers until each manufacturer's inverse demand function is tangent to its average cost function. At this output $\left(q_{i}^{*}\right)$, each manufacturer earns normal economic profits and entry ceases. ${ }^{5}$

We calculate the elasticity of entry, $\eta$, which is the percentage change in the equilibrium number of generic entrants 12 months after patent expiration in response to a $1 \%$ increase in fixed costs:

$\eta=\frac{F \partial N^{*}}{N^{*} \partial F}=\frac{-(a-m)}{2(a-m-\sqrt{b} \sqrt{F})}$.

Given that $b, F>0$, it follows that $\eta \geqslant-0.5$. Not only is -0.5 an upper bound for the elasticity and thus a conservative estimate it is also a reasonable estimate. The generic pharmaceutical industry is characterized by high value, relatively low prices, and low costs of entry and manufacturing, so it is reasonable to assume that in the generic pharmaceutical industry $\sqrt{b} \sqrt{F}$ is small. For example, if the maximum willingness to pay is $\$ 6000$ per year $(\$ 500$ per month), $b=-0.1$, 
and fixed costs are $\$ 1$ million then the elasticity of entry is -0.53 . If fixed costs are smaller and/or willingness to pay is greater then the elasticity approaches -0.5 . An entry elasticity of -0.5 implies that if fixed costs rise by $10 \%$ then the equilibrium number of generic firms decreases by $5 \%$.

We have demonstrated that higher fixed costs decrease firm entry. We now consider the impact of higher costs on prices. When firm entry is in equilibrium, the profit-maximizing price for a generic manufacturer is $p_{g}^{*}=m g+\sqrt{b} \sqrt{F_{g}}$. When the branded manufacturer is a monopolist $(N=1)$ then the profit maximizing price is $p_{b}^{*}=\left(a+m_{b}\right) / 2$. In equilibrium the ratio of the generic price after patent expiration to the branded price pre-patent expiration is

$\frac{p_{g}^{*}}{p_{b}^{*}}=\frac{2\left(m_{g}+\sqrt{b} \sqrt{F_{g}}\right)}{a+m_{b}}$.

From Equation (3) we see that an increase in marginal costs for generics $\left(m_{g}\right)$ or a decrease in marginal costs for branded drugs $\left(m_{b}\right)$ leads to higher generic prices relative to branded prices. If, however, marginal costs are comparable for generic and branded products, then the impact of marginal costs on the price ratio will be muted, because marginal costs appear in both numerator and denominator. On the other hand, the impact of higher fixed costs is not offsetting. An increase in fixed costs for generics $\left(F_{g}\right)$, leads to an increase in prices for generics relative to branded products $\left(p_{g} * / p_{b} *\right)$ because high fixed costs deter generic entry and diminish competition. An increase in fixed costs for branded products does not affect the price ratio (conditional on branded entry). Hence, when comparing generic pharmaceuticals to generic biologics, we expect that higher marginal costs for biologics to have a muted effect on the price ratio and higher fixed costs for biologics to have a substantial effect on the price ratio.

\section{Fixed Costs}

We examine three fixed costs: clinical trials, capital costs, and manufacturing. We expect that all of these fixed costs will be higher for generic biologics than for generic pharmaceuticals. First, FDA approval will require more clinical testing for generic biologics than for generic pharmaceuticals.
For pharmaceutical generics, demonstrating bioequivalence with the branded product is sufficient. In biologics, 'the process makes the product,' meaning that minor modifications in a bioprocess can lead to variations in quality and safety. Hence, the FDA could require clinical trials in order to demonstrate that generics have sufficiently similar safety and efficacy with the branded products. The average phase III study for branded pharmaceuticals to gain FDA approval costs $\$ 86$ million and typically enrolls several thousand patients (DiMasi et al., 2003). Even if the phase III study required for generic biologic approvals only involves several hundred patients, it would still increase entry cost by many millions of dollars compared to the costs normally incurred under the bioequivalence requirements for generic pharmaceuticals. Furthermore, there would be an opportunity cost given that development time could be 5-8 years (1-2 years for cell biology, 1 year for process analysis, 2-4 years for clinics, and 1 year for approval) (Bio Generix, 2005). Generic manufacturers will try to decrease their clinical trial obligations by identifying the structure and content of biologic molecules using technology such as mass spectrometry and crystallography (Abboud, 2005).

Second, capital investment outlays will be significantly greater for generic biologics than for generic pharmaceuticals. Facility construction can take 4-5 years and cost $\$ 250$ to $\$ 400$ million (Molowa, 2001), though this fixed cost might be spread over multiple products. In addition, firms can enter into partnership agreements based on geographical locations. Some facilities could be located in China, India, or Singapore to reduce unit labor costs, but facility costs in those countries may be comparable to costs in the United States if the manufacturer complies with FDA standards. An alternative to manufacturing in-house is contract manufacturing. Due to current scarcity of capacity, however, contract manufacturers have considerable leverage in negotiations and are selective in choosing projects (Molowa, 2001). Contract manufacturers are more likely to use their limited capacity to continue relationships with innovators than to ally with generics (Polastro and Little, 2001). Eventually, greater capacity will be available, but contract manufacturing for generic biologics will still be more costly than for pharmaceuticals due to the high variable cost of production. ${ }^{6}$ 
Third, process approval and subsequent manufacturing costs are higher for biologics than for chemical entities. Regulators require manufacturers to describe the cell line and demonstrate that it is free of bacteria, fungi, adventitious viruses, and retroviruses. The manufacturer must demonstrate freedom from contamination and molecular integrity of the bulk material. Furthermore, the manufacturer must document quantity, potency, purity, sterility, and stability of the final product. Reproducibility and variability of each assay must be documented using defined procedures. Any changes in the approved manufacturing protocol require rigorous physicochemical characterization of the product and in vitro functional comparisons. Even after FDA approval, if a firm adjusts its manufacturing process, it might be required to complete additional clinical trials (Molowa, 2001).

There is, of course, cost heterogeneity across generic biologics. Some products will be easier to manufacture (e.g. human growth hormone is thought to be one of the easier biologics to manufacture) and some products will have lower clinical requirements (e.g. regulators might not be as concerned about small differences in efficacy for human growth hormone as they are for cancer treatments).

In Table 1 we compare fixed costs for pharmaceuticals vs biologics. For pharmaceutical generics, we estimate that the fixed cost is around \$2 million, based on Reiffen and Ward (2005), who estimated that the cost for research and regulatory approval in the early 1990s was $\$ 603000$, and a more recent report in The Economist (2005) that the cost is 'a couple of million dollars. ${ }^{7}$ For biologic generics, we estimate that the fixed cost could be $\$ 2$ million to more than $\$ 200$ million. The cost will be on the low end if bioequivalence is sufficient for FDA approval and if contract manufacturing is readily available. The cost will be on the high end if FDA requires testing in humans and if manufacturing costs are high.

We turn now to evidence from the generic pharmaceutical industry on the impact of market size on entry and prices. We will estimate entry and prices for generic biologics based on results from generic pharmaceuticals (below) with an adjustment for fixed costs based on Table 1 and Equation (2).

\section{Market Entry for Generic Pharmaceuticals}

We use data on generic pharmaceuticals to inform our simulations for generic biologics. For the pharmaceutical market we use IMS Health's Generic Spectra data on 40 pharmaceuticals with patent expirations between 1992 and 1998 as reported in Saha et al. (2006) (Table 2). The sample is limited to oral pharmaceuticals prescribed primarily for outpatients. We estimate parsimonious models to facilitate simulations and transparency.

First we estimate generic pharmaceutical entry as a function of market size.

$\ln (N)=B_{0}+B_{1} \ln (\Psi)+B_{2} \rho$.

According to Equation (4), the natural $\log$ of the number of generic firms ${ }^{8} 1$ year after initial generic entry $(N)$ is a function of the natural $\log$ of the sales of the branded product prior to generic entry $(\Psi)$. We also include an indicator variable for whether the product had restricted use $(\rho=1$ for Clozaril, Mexitil, Toradol, and Zarontin). ${ }^{9}$ We hypothesize that sales in the pre-entry period will be a key factor positively affecting the number of generic entrants. At the same time, we hypothesize that drugs subject to special usage restrictions will attract less generic entry, ceteris paribus (Saha et al., 2006).

Table 1. Components of fixed costs for generics

\begin{tabular}{lll} 
& Pharmaceuticals & Biologics \\
\hline Clinical research & Bioequivalence & Might require human testing \\
Regulatory & Licensure & Licensure \\
Manufacturing & Clinical process, existing capacity within & Biologic process, high fixed costs, and \\
& firms, and contract manufacturing available & questionable availability of contract manufacturing \\
Total fixed costs & $\$ 2$ million & $\begin{array}{l}\text { \$2 million (bioequivalence, manufacturing availability) } \\
\text { to more than \$200 million (human testing, high } \\
\end{array}$ \\
& & manufacturing costs) \\
\hline
\end{tabular}


Table 2. Generic pharmaceutical data

\begin{tabular}{|c|c|c|c|c|c|c|}
\hline Product & Class & $\begin{array}{l}\text { Generic } \\
\text { launch }\end{array}$ & $\begin{array}{l}\text { Market size } \\
\text { at entry } \\
\text { (in } 2000 \$ \mathrm{~m} \text { ) }\end{array}$ & $\begin{array}{l}\text { Generic share } \\
12 \text { months after } \\
\text { generic entry } \\
(\%)\end{array}$ & $\begin{array}{l}\text { Generic Price } 12 \\
\text { months after generic } \\
\text { entry to branded } \\
\text { price pre-entry }(\%)\end{array}$ & $\begin{array}{l}\text { Number generics } \\
12 \text { months after } \\
\text { generic entry }\end{array}$ \\
\hline Zantac & Gastrointestinal & Jul-97 & $1,856.94$ & 75 & 34 & 13 \\
\hline Tagamet & Gastrointestinal & May-94 & 875.40 & 66 & 46 & 19 \\
\hline Xanax & $\begin{array}{l}\text { Psychotherapeutic/ } \\
\text { sedative }\end{array}$ & Sep-93 & 805.49 & 72 & 10 & 20 \\
\hline Naprosyn & Analgesic & Sep-93 & 697.05 & 85 & 17 & 18 \\
\hline Ceclor & Anti-infective & Oct-94 & 656.71 & 83 & 73 & 8 \\
\hline Capoten & Cardiovascular & Dec-95 & 639.75 & 79 & 5 & 21 \\
\hline Zovirax & Anti-infective & Apr-97 & 573.37 & 86 & 44 & 20 \\
\hline Cardizem & Cardiovascular & Oct-92 & 557.67 & 64 & 26 & 13 \\
\hline Lopid & Cardiovascular & Jan-93 & 539.03 & 63 & 67 & 8 \\
\hline Klonopin & Neurological disorder & Sep-96 & 395.95 & 72 & 70 & 3 \\
\hline Lopressor & Cardiovascular & Oct-93 & 371.26 & 58 & 33 & 13 \\
\hline Lodine & Analgesic & Feb-97 & 343.83 & 59 & 51 & 12 \\
\hline Voltaren & Analgesic & Aug-95 & 331.17 & 81 & 64 & 6 \\
\hline Glucotrol & Diabetes & May-94 & 288.60 & 58 & 64 & 10 \\
\hline Clozaril & $\begin{array}{l}\text { Psychotherapeutic/ } \\
\text { sedative }\end{array}$ & Dec-97 & 281.73 & 10 & 65 & 1 \\
\hline Diabeta & Diabetes & Apr-94 & 263.43 & 77 & 61 & 7 \\
\hline Sinemet & Neurological disorder & Jan-93 & 205.89 & 28 & 63 & 9 \\
\hline Corgard & Cardiovascular & Aug-93 & 185.32 & 45 & 79 & 4 \\
\hline Carafate & Gastrointestinal & Nov-96 & 159.72 & 66 & 66 & 2 \\
\hline Ansaid & Analgesic & Jun-94 & 154.97 & 72 & 60 & 5 \\
\hline Orudis & Analgesic & Dec-92 & 145.02 & 62 & 40 & 12 \\
\hline Lozol & Cardiovascular & Jul-93 & 143.41 & 42 & 75 & 2 \\
\hline Eldepryl & Neurological disorder & Aug-96 & 118.84 & 41 & 41 & 6 \\
\hline Tenoretic & Cardiovascular & Jul-92 & 101.50 & 39 & 67 & 6 \\
\hline Dolobid & Analgesic & Oct-92 & 98.29 & 58 & 51 & 9 \\
\hline Parlodel & Neurological disorder & Jan-98 & 82.91 & 33 & 69 & 3 \\
\hline Halcion & $\begin{array}{l}\text { Psychotherapeutic/ } \\
\text { sedative }\end{array}$ & Sep-93 & 74.78 & 50 & 63 & 9 \\
\hline Bumex & Cardiovascular & Jan-95 & 69.64 & 34 & 77 & 4 \\
\hline Anafranil & $\begin{array}{l}\text { Psychotherapeutic/ } \\
\text { sedative }\end{array}$ & Dec-96 & 59.43 & 67 & 49 & 5 \\
\hline Toradol & Analgesic & May-97 & 50.89 & 70 & 65 & 2 \\
\hline Visken & Cardiovascular & Oct-92 & 50.06 & 34 & 58 & 10 \\
\hline Sectral & Cardiovascular & May-95 & 47.71 & 46 & 72 & 1 \\
\hline Mexitil & Cardiovascular & Jun-95 & 42.42 & 40 & 66 & 5 \\
\hline $\begin{array}{l}\text { Capozide } \\
\text { Cardiovascular }\end{array}$ & Cardiovascular & Dec-97 & 39.80 & 48 & 39 & 5 \\
\hline Cardene & Cardiovascular & Jul-96 & 27.47 & 40 & 62 & 4 \\
\hline $\begin{array}{l}\text { Wytensin } \\
\text { Cardiovascular }\end{array}$ & Cardiovascular & Sep-94 & 15.30 & 43 & 56 & 6 \\
\hline Prosom & $\begin{array}{l}\text { Psychotherapeutic/ } \\
\text { sedative }\end{array}$ & Jul-97 & 14.97 & 44 & 63 & 3 \\
\hline Aventyl & $\begin{array}{l}\text { Psychotherapeutic/ } \\
\text { sedative }\end{array}$ & Jul-92 & 13.60 & 97 & 64 & 1 \\
\hline Zarontin & Neurological disorder & Aug-94 & 11.92 & 1 & 75 & 1 \\
\hline Vivactil & $\begin{array}{l}\text { Psychotherapeutic/ } \\
\text { sedative }\end{array}$ & Мay-96 & 6.55 & 26 & 66 & 3 \\
\hline Mean & & & 285 & 55 & 55 & 8 \\
\hline
\end{tabular}

Source: IMS Generic Spectra audit data as reported in Saha et al., (2006).

\section{Relative Prices for Generic Pharmaceuticals}

Next, we can estimate the relative prices for generics given market entry. Using the generic pharmaceutical data from IMS, we regress the natural $\log$ of the ratio of the generic price measured 1 year after the initial generic entry $\left(p_{g e n}\right)$ to the branded price measured prior to generic entry $\left(p_{\text {brand }}\right)$ on the number of generic firms for a given molecule $(N) .{ }^{10}$ The regression equation also controls for time trend $(t=1$ for $1992, \ldots t=7$ for 1998) and for the therapeutic 
class of a drug, $X$, as denoted by the dummy variables listed in Table 1.

$\ln \left(p_{\text {gen }} / p_{\text {brand }}\right)=B_{3}+B_{4} N+B_{5} t+B_{6} X$.

Equation 5 expresses the $\log$ of the price ratio as a function of the number of generic firms. ${ }^{11}$ Alternatively, by using Equations (4) and (5), the price ratio can be expressed as a function of the pre-generic market size: $p_{\text {gen }} / p_{\text {brand }}=$ $\operatorname{Exp}\left[B_{3}+B_{4} \operatorname{Exp}\left[B_{0}+B_{1} \ln (\Psi)+B_{2} \rho\right]+B_{5} t+B_{6} X\right]$.

Under other circumstances, modeling relative prices as a function of the number of firms would raise concerns about endogeneity, because the number of firms might be a function of relative prices. In this case, however, the stochastic nature of FDA approval makes the timing of entry decisions largely an exogenous event. In particular, the firm engages in a regulatory process over time with the FDA concerning the chemical, manufacturing, and bioequivalence studies necessary to gain approval. In many cases, the FDA finds the initial abbreviated new pharmaceutical application (ANDA) deficient and requires additional tests or materials. Approval might require two or three resubmissions (Reiffen and Ward, 2005). Between 1992 and 1997 the average annual time between the initial application and approval of ANDAs varied between 1.5 and 3.0 years, with significant additional variability across firms and products (Saha et al., 2006). Furthermore, entry requires time to obtain materials and adequate production, particularly for biologics. Hence, it is unlikely that the number of firms at a point in time is affected by current prices (Reiffen and Ward, 2005). This stochastic timing of approvals mitigates the endogeneity problem of measuring the relationship between price and the number of competitors.

\section{Market Entry and Prices for Generic Biologics}

The market for generic pharmaceuticals provides insight into the market for generic biologics, but an important difference between pharmaceuticals and biologics is the cost of production. If costs are higher for biologics, then market entry will be smaller for a given level of sales.

We assume that the number of generic entrants at 12 months for biologics is a function of the number of generic entrants for pharmaceuticals multiplied by an adjustment factor so $N_{\text {bio }}=N$ $(1+\delta N / N)$. From Equation (2), $\delta N / N=\eta \delta F / F$.
From Equation (4) $N=\mathrm{e}^{B_{0}+B_{1} \psi+B_{2} \rho}$. Substituting yields

$N_{\text {bio }}=\left(1+\eta \frac{\partial F}{F}\right) \mathrm{e}^{B_{0}+B_{1} \psi+B_{2} \rho}$.

The number of generic entrants at 12 months for biologics is a function of the elasticity of entry $(\eta)$, the percentage change in fixed costs in moving from pharmaceuticals to biologics $(\delta F / F)$, the parameter estimates from the pharmaceutical regression $\left(B_{0}, B_{1}, B_{2}\right)$, market size $(\Psi)$, and restrictions on product use $(\rho)$.

We now consider the ratio of the generic price to the branded price 12 months after the first generic entry. We take the price ratio from Equation (5) (for the pharmaceutical industry) for a given number of generic biologic manufacturers $N_{\text {bio }}$ from Equation (6). For biologics:

$$
\begin{aligned}
\frac{p_{\text {gen }, \text { bio }}}{p_{\text {brand }, \text { bio }}}= & \operatorname{Exp}\left[B_{3}+B_{5} t+B_{6} X\right. \\
& \left.+B_{4}\left(1+\eta \frac{\partial F}{F}\right) \mathrm{e}^{B_{0}+B_{1} \psi+B_{2} \rho}\right] .
\end{aligned}
$$

In Equation (7), the price of a generic biologic relative to the branded price depends upon the year $(t)$, therapeutic class $(X)$, elasticity of entry $(\eta)$, the percentage increase in fixed costs over pharmaceuticals $(\delta F / F)$, pre-generic market size $(\Psi)$, and restrictions on product use $(\rho)$.

\section{RESULTS}

\section{Generic Pharmaceutical Entry}

We find that the number of generic pharmaceutical manufacturers is increasing with market size and decreasing with restrictions on product use, and both variables are statistically significant (Table 3). Because the regression is in logs, the coefficient can be interpreted as an elasticity. For a product with no restrictions, a $10 \%$ increase in the level of branded sales prior to patent expiration leads to a $4 \%$ increase in the number of generic manufacturers in the market 12 months after the first generic entrant. We also added therapeutic class dummies and a time trend in a separate set of regression estimates. However, because these variables were insignificant (with $t$-values less than 1) and the other results unchanged, we did not report these results in the table.

Manage. Decis. Econ. 28: 439-451 (2007) DOI: $10.1002 / \mathrm{mde}$ 


\section{Table 3. Results from generic pharmaceutical entry}

\begin{tabular}{lclc} 
Variable & $\begin{array}{l}\text { Parameter } \\
\text { estimate }\end{array}$ & $\begin{array}{l}\text { Standard } \\
\text { error }\end{array}$ & $p$-value \\
\hline Intercept & 0.07 & 0.40 & 0.86 \\
Log of the market size & 0.36 & 0.08 & $<0.0001$ \\
Restricted use & -0.90 & 0.35 & 0.01 \\
\hline
\end{tabular}

The dependent variable is the natural log of the number of generic manufacturers of a given molecule. Adjusted $R^{2}=0.46$.

\section{Table 4. Results from generic pharmaceutical pricing}

\begin{tabular}{lclc} 
Variable & $\begin{array}{l}\text { Parameter } \\
\text { estimate }\end{array}$ & $\begin{array}{l}\text { Standard } \\
\text { error }\end{array}$ & $p$-value \\
\hline Intercept & 0.00 & 0.20 & 1.00 \\
Number generic & -0.09 & 0.01 & $<0.0001$ \\
manufacturers & & & \\
Time trend & -0.05 & 0.03 & 0.10 \\
Analgesic & 0.23 & 0.18 & 0.21 \\
Anti-infective & 0.93 & 0.28 & 0.00 \\
Cardiovascular & 0.08 & 0.15 & 0.59 \\
Diabetes & 0.46 & 0.26 & 0.09 \\
Gastrointestinal & 0.52 & 0.23 & 0.03 \\
Neurological disorder & 0.16 & 0.19 & 0.41 \\
\hline
\end{tabular}

The dependent variable is the natural $\log$ of the ratio of the generic price to the branded price. Psychotherapeutic/sedative is the omitted therapeutic class. Adjusted $R^{2}=0.65$.

\section{Generic Pharmaceutical Prices}

We find that the generic price is closer to the branded price when there are fewer entrants (Table 4). The results imply that the expected generic-to-brand price ratio is $90 \%$ with one entrant, $63 \%$ with five entrants, and $40 \%$ with 10 entrants. These estimates are at the sample means for the time trend and class dummy variables. We also find that generic prices are relatively lower in later years and that relative prices vary by therapeutic class, including higher relative prices for generic anti-infectives. This latter finding may reflect the acute nature of treatment for anti-infectives. Some researchers have found more intense price competition for chronic compared to acute therapies ( $\mathrm{Lu}$ and Comanor, 1998).

\section{Generic Biologic Entry}

In Figure 2 we plot the estimated market entry for generic pharmaceuticals as a function of market

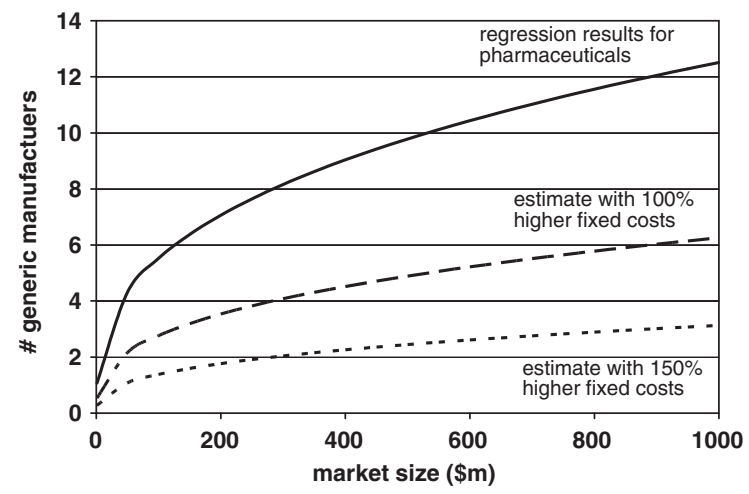

Figure 2. Estimated number of generic manufacturers 12 months after the first generic entry as a function of branded market size ( $\$$ million) prior to generic entry.

size prior to generic entry using the results from the first regression. We anticipate that the curve will be lower for generic biologics, but the extent to which it is lower depends upon the increase in fixed costs and on the elasticity of entry. The dashed lines illustrate generic biologic entry if the entry elasticity $(\eta)$ equals -0.5 and if fixed costs are 100 or $150 \%$ higher for generic biologics. We consider the $100 \%$ case to be an upper bound for entry because the fixed costs would likely be considerably higher.

There are a number of blockbuster biological products with annual sales of $\$ 1$ billion now facing patent expiration (Humphreys, 2004). In Figure 2, if the pharmaceutical market size is $\$ 1$ billion, then we expect that on average 12 generic pharmaceutical manufacturers would enter by the end of the first year of generic competition. If fixed costs were $100 \%$ higher, our model predicts six generic firms would enter, and if fixed costs were $150 \%$ higher (still a conservative estimate), three generic firms would enter. In the next section we consider the impact of this limited generic competition on generic prices.

\section{Generic Biologic Prices}

In Figures 3 and 4 we plot the estimated ratio of generic price to branded price 12 months after generic entry with the time trend set at the midpoint and the therapeutic class variables set at their sample means (i.e. effectively a weighted average of the estimates across all the classes). 


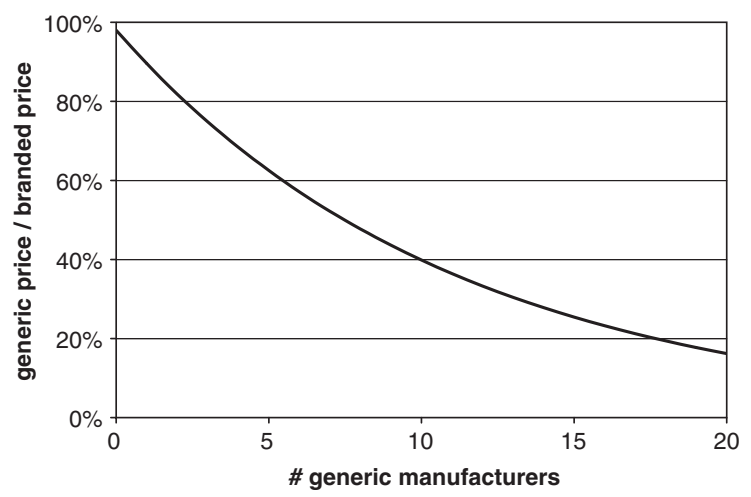

Figure 3. The ratio of generic price to branded price as a function of the number of generic manufacturers.

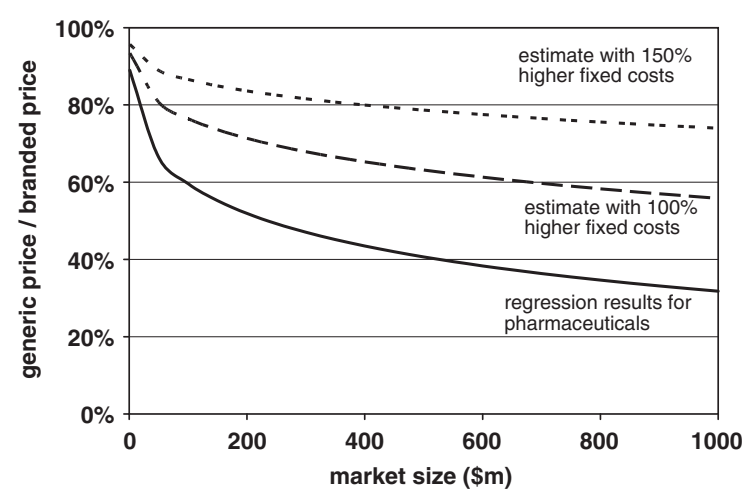

Figure 4. The ratio of generic price to branded price as a function of market size.

In Figure 3 the price ratio is a function of the number of generic manufacturers. In the aforementioned example of a $\$ 1$ billion dollar product, if there are 12 generic manufacturers, then generic prices are expected to be only $33 \%$ of branded prices, but if there are 3 manufacturers, then generic prices are expected to be $75 \%$ of the branded price. For the case of one generic entrant, which could prevail in many large biologic markets for a lengthy period of time, generic prices would be $90 \%$ of the branded price, given the estimates in our model.

Because the number of manufacturers is a function of market size, we can plot the price ratio against market size as in Figure 4. In Figure 4 we also simulate the market for generic biologics using Equation (7) and the regression coefficients. In both Figures 2 and 4 the dashed lines illustrate generic biologic entry if the entry elasticity $(\eta)$ equals -0.5 and if fixed costs are 100 or $150 \%$ higher for generic biologics.

\section{DISCUSSION}

Generic pharmaceuticals provide substantial financial benefit to individual consumers and third-party payers in the United States. The generic pharmaceutical industry was stimulated by the Hatch-Waxman Act and now represents more than $50 \%$ of the US prescription pharmaceutical market by volume. Given the benefits of generic pharmaceuticals in the United States, policy makers are exploring whether consumers will receive the same benefits from the development of a regulatory framework for generic biologic products.

Generic pharmaceuticals provide a substantial price discount over branded products. Nevertheless, it is not the mere presence of a generic product in the market but competition between multiple firms that results in aggressive price competition and discounting. To assess the potential economic advantages to consumers from generic biologic products we must assess the potential for firm entry into this new market and whether competition among manufacturers of generic biologics is likely to be as vigorous as that of manufacturers of generic pharmaceuticals. In this paper, we predict firm entry based on models of monopolistic competition. In the models, market entry is related to the fixed costs of development as well as potential revenues from market entry. In contrast to Bresnahan and Reiss (1991) we find that prices continue to fall as more firms enter, even when there are already several competitors.

Since the specific requirements for generic biologic products do not yet exist, we developed a framework for assessing the initial investment required for firms to enter this market. Here, there might be substantial differences between generic pharmaceuticals and generic biologics. Most policy experts anticipate that generic biologics will entail some clinical testing in humans, a process that will require substantially more investment than bioequivalence testing for generic pharmaceuticals.

In our model, entry was limited by high fixed costs, which decreased expected returns. Entry might also be limited by capacity constraints. Although there are exceptions, companies tend to specialize in either pharmaceuticals or biologics due to substantial differences in manufacturing, clinical trials, and regulatory approval. Furthermore, companies tend to specialize in generics or 
branded pharmaceuticals because of differences in culture and consistency of message. In the case of conjugated hormonal contraceptives, for example, only a handful of generic firms have entered the market, and even the most widely used products have only two or three generic competitors. If these types of specializations persist, we might anticipate that the market for generic biologics will be filled in part with start-ups. However, start-ups will have trouble raising capital to cover the high fixed costs of entry. Thus, in the short run, entry and output could be limited by a dearth of manufacturers and capacity constraints of those manufacturers, unless contract manufacturing fills this gap.

The availability of contract manufacturing will affect costs and prices. Manufacturing biologics typically requires the development of specific production facilities and certified processes, a substantial difference from the inorganic chemistry and bulk production techniques of pharmaceutical manufacturing. If generic firms were required to develop their own production facilities, this would have a substantial negative impact on entry (beyond our current estimates). If contract manufacturing is available in the market, the fixed component of the contract price could be substantial, but not as great a barrier as the full cost of internal manufacturing capacity.

We expect the aforementioned factors to reduce entry and price competition in the marketplace, relative to generic pharmaceuticals. Over a considerable period of time, manufacturing and regulatory costs might fall due to technological innovation and familiarity by regulators. Under these circumstances, the market for generic biologics would approach that of generic pharmaceuticals, but this is unlikely for the foreseeable future.

\section{Qualifications and Future Research}

We used a long-term equilibrium analysis of symmetric generic entrants ${ }^{12}$ for the sake of analytical tractability and to illuminate the important role of higher fixed costs on the supply side of the market as a factor limiting generic entry in biologics. A limitation of the study is that we use a 1 -year horizon in our empirical analysis of generic pharmaceuticals to simulate equilibrium entry and prices. Nevertheless, the assumption that markets in generic pharmaceuticals converge to equili- brium within a year's time is a reasonable approximation for the case of a large-selling pharmaceutical. This is the primary case of interest in our analysis. In particular, the potential of large sales combined with low costs of entry attracts a large number of entrants and rapid convergence toward equilibrium price levels for generic pharmaceuticals.

Another limitation is that we use elasticities which are best applied to small percentage changes. Here, the difference between fixed costs for generic biologics vs generic pharmaceuticals could be more than $200 \%$. More insight could be gained from US generic pharmaceuticals with a richer data set enabling a more structural model, but any forecast is likely to be imprecise given uncertainties about regulations and costs for generic biologics.

There are a number of interesting issues to explore in further research concerning demand side factors. First, it would be interesting to explore demand side differences between pharmaceuticals and biologics that could affect entry. In contrast to oral pharmaceuticals, large-molecule injectible biologics are typically dispensed by physicians in clinics or hospitals and for at-risk patient populations with diseases like cancer. In this environment, physicians and providers might be very cautious in embracing generic biologics until widespread market experience demonstrates their safety and efficacy. Consequently, generic biologic firms might find it optimal to invest in substantial physician education and detailing. Indeed, they might even pursue a strategy of branded generics, which would entail extra upfront expenses but also enhance early mover advantages. Detailing and branding are rare for generic pharmaceuticals due to strong economic incentives for physicians, pharmacists, and patients to substitute generics for the branded alternative (e.g. three tier formularies, mandatory generic substitution, and higher margins to pharmacists for generics).

A second direction for further analysis is the response of the innovator firm to generic biologics. Brand firms have generally eschewed significant price competition with pharmaceutical generics. ${ }^{13}$ Rather, they have opted for life cycle management strategies such as the introduction of a new dosage formulation or a shift to over-the-counter status. This might be changing with the emergence of 'authorized generic' strategies, particularly in cases 
where a single generic firm holds 180-day exclusivity as part of a successful patent challenge (Reiffen and Ward, 2007). Innovators in biologics, faced with the threat of generic entry, might combine both life cycle management strategies (e.g. new patent-protected product improvements) with authorized generic strategies for earliergeneration products. This is another factor that could affect entry and the equilibrium levels of firms.

\section{Policy Options}

We assume that regulatory requirements for generic biologics will be driven by safety concerns and will include at least some clinical trial data related to safety and efficacy. We forecast that limited entry in the market for generic biologics will result in generic prices that are relatively close to branded prices. To decrease prices the government could create incentives for greater entry using push or pull mechanisms. Push mechanisms decrease fixed costs (e.g. grants for translational medicine, easing regulations, encouraging contract manufacturing capabilities) whereas pull mechanisms subsidize returns (e.g. 180-day exclusivity for the first generic pharmaceutical). Both push and pull mechanisms are intended to encourage entry and drive down long-run prices.

It is not clear, however, that push or pull mechanisms would enhance social welfare. Consider each of the players. For innovators, returns would fall due to increased generic competition. For generic manufacturers, the expected impact would be neutral because there is free entry and subsidies would drive down both costs and also prices. For taxpayers, lower prices might be offset by the cost of subsidies, particularly if the subsidies pay for duplicative fixed costs. In the presence of economies of scale, it can be particularly inefficient to pay subsidies to reduce fixed costs for multiple manufacturers.

Given uncertainty about the market for generic biologics, it is challenging to accurately forecast the market. Nevertheless, we can use economic theory and empirical observation of generic pharmaceuticals to gain a better understanding of the likely market for generic biologics. We find that high fixed costs of entering the market for generic biologics will create less entry than would be predicted for generic pharmaceuticals. We also expect that generic biologics will be relatively close in price to branded biologics for the foreseeable future. Policy makers should be cautious in projecting large financial benefits from generic biologics for consumers and payers based on the experiences of generic pharmaceuticals. They should consider how generic biologics will differ in terms of economics as well as scientific and regulatory factors.

\section{Acknowledgements}

This research was supported in part by a grant from Genentech to Duke University. The design, analysis, and writing of the manuscript were conducted independently by the authors. We thank Ernst Berndt and Tomas Philipson for helpful comments.

\section{NOTES}

1. Throughout the paper we refer to 'generic biologics' for the sake of symmetry with generic pharmaceuticals. The term 'follow-on biologic' might be more appropriate than 'generic biologic,' given that the product might be required to complete clinical trials to demonstrate similar safety and efficacy to the originator.

2. In 2006 FDA approved Omnitrope, but the agency called it a "follow-on protein product" rather than generic biologic. Omnitrope is neither therapeutically equivalent to nor substitutable for any of the other human growth hormone products. FDA declared that in approving Omnitrope it was not creating a pathway for other generic products, because such a pathway requires legislation. Omnitrope had already been approved in Europe and Australia.

3. In addition to our research, the Congressional Budget Office and the Office of Management and Budget have been charged with estimating the impact of generic biologics on US government health care costs.

4. Brand loyalty, buyer inertia, and other demand side effects could lead to divergences in the dynamic path of prices across firms and even 'harvesting strategies' in which branded prices increase in the post-entry period (Frank and Salkever, 1997). The potential role of early mover advantages and demand side differences across firms are considered under topics for further research.

5. An alternative model would allow the branded firm to commit to high output and low price and thus deter entry by generics. This pre-emptive strategy has not been observed in the case of generic pharmaceuticals, but other life cycle management strategies such as line extensions and authorized generics have been employed. These are discussed in the section on qualifications and future research.

6. Frost and Sullivan, (2003) estimated that total worldwide capacity was approximately two million liters in 2003 with planned expansion to three million liters in 2006. Furthermore, contract man- 
ufacturers held approximately $65 \%$ of worldwide capacity in 2003.

7. These estimates are for the costs of performing bioequivalence tests and other procedures to gain FDA approval. Most generic pharmaceutical firms have large plants with multiple products. Hence, fixed costs for manufacturing are already spread over a large number of established generic products and there is typically excess capacity to undertake new product offerings. This situation suggests that fixed costs of manufacturing are low for generic pharmaceutical firms in contrast to the current situation for generic biologics.

8. IMS is the source for data on the number of generic competitors and annual sales in the pre-entry period. In other analyses of generic entry (Scott Morton, 1996; Reiffen and Ward, 2005), the number of abbreviated new drug approvals (ANDAs), which is available on the FDA Web site, serves as a proxy for the number of generic competitors. We observed, however, that the number of generic competitors is typically greater than the number of ANDAs due to licensing agreements between generic firms and 'formulators' that supply multiple generic firms with a product (Saha et al., 2006).

9. Each of these products has special usage restrictions (e.g. requirements to start patients with in-hospital intravenous delivery, weekly monitoring, etc). These restrictions are mandated by the FDA because of the presence of potentially serious side effects. These products also raise particular liability considerations for generic manufacturers.

10. Prices for both the branded and generic firms are measured in dollars per gram of product.

11. The semi-log functional form provided a superior explanation of variance (adjusted $R^{2}$ ) compared to a $\log -\log$ or linear form.

12. In the long run, expected economic profits should be normal, but ex post economic profits might be negative if too many generic manufacturers enter the market. This problem of simultaneity might be mitigated if firms can observe one another's construction of manufacturing capacity and thus credibly deter additional capacity and production by rivals.

13. The impact of generic entry on branded price is unclear. On the one hand, the branded manufacturer could lower its price to compete with the generic. Alternatively, the branded manufacturer might raise the price because its remaining customers are less price-responsive. Previous researchers have found a small positive effect of generic entry on branded price (Frank and Salkever, 1997; Grabowski and Vernon, 1992) or a small negative effect of generic entry on branded price (Caves et al., 1991) (Saha et al., 2006). Bhattacharya and Vogt (2002) found a large negative effect of generic entry on branded prices. In our sample, only Tagamet had a lower price one year after the first generic entry, though some branded manufacturers increased their prices slower than the rate of inflation. Twenty-eight of forty manufacturers increased their prices faster than the rate of inflation (pharmaceutical producer price index).

\section{REFERENCES}

Abboud L. 2005. One start-up's path to making biotech clones. Wall Street Journal, August 16, 2005; B1. Available at: http://online.wsj.com/article/0, SB112414810785913821,00.html. Accessed August 16, 2005.

Alonso-Zaldivar R. 2005. For generic pharmaceuticals, the price is right in U.S. Los Angeles Times, August 9, 2005. Available at: http://www.latimes.com/news/ nationworld/nation/la-na-pharmaceuticals9_aug09,1, 3367959.story. Accessed August 16, 2005.

Bhattacharya J, Vogt WB. 2003. A simple model of pharmaceutical price dynamics. Journal of Law and Economics 46: 599-626.

Big Generic Pharma. 2005. The Economist, July 28, 2005. Available at: http://www.economist.com/ research/articlesBySubject/PrinterFriendly.cfm?Story_ID $=4233872 \&$ subjectID $=531766$. Accessed August 16, 2005.

Bio Generix Presentation. 2005. Follow-on Biologics Forum: The Delivery of Regulatory, Legal and Business Strategies Balanced by Scientific DebatesWashington, DC, April 27-29, 2005.

Bresnahan T. 1989. Empirical studies of industries with market power. In Handbook of Industrial Organization, Vol. 2, Schmalensee R, Willig RD (eds). Elsevier Ltd: Oxford, UK; 1011-1057.

Bresnahan T, Reiss P. 1991. Entry and competition in concentrated markets. Journal of Political Economy 91: 977-109.

Caves RE, Whinston MD, Hurwicz MA. 1991. Patent expiration, entry, and competition in the U.S. pharmaceutical industry. Brookings Papers on Economic Activity: Microeconomics; 1-66.

Chamberlin EH. 1933. The Theory of Monopolistic Competition. Harvard University Press: Cambridge.

DiMasi JA, Hansen RW, Grabowski HG. 2003. The price of innovation: new estimates of pharmaceutical development costs. Journal of Health Economics 22: 151-185.

Frank R, Salkever D. 1997. Generic entry and the pricing of pharmaceuticals. Journal of Economics and Management Strategy 6: 75-90.

Frost \& Sullivan. 2003. Biopharmaceutical Industry Analysis-Quantification of Supply and Demand of Manufacturing Analysis, November 2003.

Frost \& Sullivan. 2005. Strategic Analysis of the World Biogenerics Markets. B613-52 http://www.frost.com/ prod/servlet/report-homepage.pag?repid $=$ B613-0100-00-00.

Grabowski H, Vernon J. 1992. Brand loyalty, entry and price competition in pharmaceuticals after the 1984 Pharmaceutical Act. Journal of Law and Economics 35: 331-350.

Grabowski H, Vernon J. 1996. Longer patents for increased generic competition in the US: the Waxman-Hatch Act 
after one decade. Pharmacoeconomics 10(Suppl): 110123.

Humphreys A. 2004. Difficult path for biogenerics. MedAdNews, December 2004.

Lu ZJ, Comanor W. 1998. Strategic pricing of new pharmaceuticals. Review of Economics and Statistics 80: $108-118$.

Mathews AW. 2005. Suit presses generic-biotech issue. Wall Street Journal, September 14, 2005; D4.

Molowa DT. 2001. The state of biologics manufacturing. J.P. Morgan Securities Inc. Equity Research Healthcare Research Note. February 16, 2001.

Polastro ET, Little AD. 2001. The future of biogenerics. Contract Pharma Web site. Available at: http:// www.contractpharma.com/archive/2001/10/feature2. php. Accessed August 16, 2005.

Reiffen D, Ward MR. 2005. Generic pharmaceutical industry dynamics. Review of Economics and Statistics 87: $37-49$.
Reiffen D, Ward MR. 2007. 'Branded generics' as a strategy to limit cannibalization of pharmaceutical markets. Managerial and Decision Economics 28: $251-265$.

Saha A, Grabowski HG, Birnbaum H, Greenberg P, Bizan O. 2006. Generic competition in the U.S. pharmaceutical industry. International Journal of the Economics of Business 13: 15-38.

Scott Morton F. 1996. Entry decisions in the generic pharmaceutical industry. RAND Journal of Economics 30: $421-440$.

Skinner BJ. 2005. Seniors and pharmaceutical prices in Canada and the United States. Fraser Institute Digital Publication. Available at: http://www.fraserinstitute. ca/admin/books/files/Seniors\&PharmaceuticalPrices CanUS.pdf. Accessed August 16, 2005.

Wiggins SN, Maness R. 2004. Price competition in pharmaceuticals: the case of anti-infectives. Economic Inquiry 42: 247-263. 